\title{
Tesauro de Turismo e Meios de Hospedagem
}

Marilia Köenig - Doutoranda em Ciências da Linguagem. Faculdade de Tecnologia Senac Tubarão - Brasil. maiam_78@hotmail.com

Cláudia Nandi Formentin - Doutora em Ciências da Linguagem. Faculdade de Tecnologia Senac Tubarão - Brasil.

formentinnandi.claudia@gmail.com

Renato Justino Borges - Mestre em Educação. Faculdade de Tecnologia Senac Tubarão - Brasil. renato.justino@sc.senac.br

Bolsitas do PIC SENAC:

Alessandra Costa Corrêa

Ana Cristina de Souza

Denise da Silva

Edilaine Silva de Oliveira

Greice B. Lemos Burato

Hiorana Corrêa de Bairros

Paulo Fernando da Silva

Rosangela Pereira da Silva

Thais da Silva Rosendo

A lista a seguir apresenta os 226 termos identificados e definidos para a construção do Tesauro de Turismo e Meios de Hospedagem, conforme relatado em artigo publicado' nesta edição da revista Navus pelos mesmos autores.

\begin{tabular}{|c|c|c|c|c|}
\hline TERMOS & DEFINIÇÃo & PORTUGUÊS & INGLÊS & ESPANHOL \\
\hline A compartir & $\begin{array}{c}\text { Termo utilizado para } \\
\text { indicar que o Pax (ver } \\
\text { verbete) compartirá meios } \\
\text { (acomodação ou transfer). }\end{array}$ & A compartir & Sharing & La cuota \\
\hline $\begin{array}{c}\text { Alimentos e Bebidas } \\
\text { Aepartamento do hotel } \\
\text { responsável pelo controle } \\
\text { da cozinha, restaurante, } \\
\text { banquetes, room service, } \\
\text { bar e frigobar. }\end{array}$ & $\begin{array}{c}\text { Alimentos e } \\
\text { Bebidas }\end{array}$ & $\begin{array}{c}\text { Food and } \\
\text { beverages }\end{array}$ & Comidas y bebidas \\
\hline $\begin{array}{c}\text { Accompanied } \\
\text { Baggage }\end{array}$ & $\begin{array}{c}\text { Bagagem transportada na } \\
\text { mesma aeronave que o } \\
\text { pax. }\end{array}$ & $\begin{array}{c}\text { Bagagem } \\
\text { Acompanhada }\end{array}$ & $\begin{array}{c}\text { Accompanied } \\
\text { Baggage }\end{array}$ & $\begin{array}{c}\text { Equipaje } \\
\text { Acompañado }\end{array}$ \\
\hline ADining rooms & $\begin{array}{c}\text { Quartos do hotel que } \\
\text { embora localizados um ao } \\
\text { lado do outro, não têm } \\
\text { portas de comunicação. }\end{array}$ & $\begin{array}{c}\text { Quartos } \\
\text { adjacentes }\end{array}$ & Adjoining rooms & Habitaciones \\
contiguas
\end{tabular}

${ }^{1}$ KÖENIG, Marília; FORMENTIN, Cláudia Nandi; BORGES, Renato Justino. Projeto de estruturação terminológica para a área de turismo e hospitalidade: um tesauro de definições. Navus, Florianópolis, v. 6, n. esp., p. 35-42, nov. 2016. 


\begin{tabular}{|c|c|c|c|c|}
\hline & $\begin{array}{l}\text { garantido em um período } \\
\text { anterior a sua utilização. }\end{array}$ & & & \\
\hline Agentless booking & $\begin{array}{l}\text { Reserva efetuada } \\
\text { diretamente pelo cliente } \\
\text { utilizando um sistema de } \\
\text { reservas sem a } \\
\text { intermediação do agente } \\
\text { de viagens. }\end{array}$ & $\begin{array}{l}\text { Reserva sem } \\
\text { agente }\end{array}$ & Agentless booking & Reserva sin agente \\
\hline Albergue & $\begin{array}{c}\text { Estabelecimento de } \\
\text { hospedagem com recurso } \\
\text { de alimentação a preços } \\
\text { mais acessíveis. }\end{array}$ & Albergue & Hostel & Hostal \\
\hline All Inclusive & $\begin{array}{c}\text { Expressão utilizada para } \\
\text { indicar que a reserva é } \\
\text { completa, ou seja, tudo } \\
\text { incluso. }\end{array}$ & Tudo incluído & All inclusive & Todo incluido \\
\hline All Suite & $\begin{array}{l}\text { Termo que designa o hotel } \\
\text { que só possui suítes. }\end{array}$ & All suite & All suite & All suites \\
\hline Allotment & $\begin{array}{l}\text { Bloqueio efetuado por } \\
\text { uma agência de turismo } \\
\text { para unidade habitacional } \\
\text { (UH) em um hotel. }\end{array}$ & Atribuição & Allotment & Atribución \\
\hline Alta Temporada & $\begin{array}{c}\text { Período de maior } \\
\text { intensidade/procura no } \\
\text { hotel. }\end{array}$ & $\begin{array}{l}\text { Alta temporada, } \\
\text { também } \\
\text { conhecida época } \\
\text { alta }\end{array}$ & $\begin{array}{l}\text { High season } \\
\text { (peak season) }\end{array}$ & Temporada Alta \\
\hline American Breakfast & $\begin{array}{l}\text { Café da manhã americano } \\
\text { (completo). }\end{array}$ & $\begin{array}{l}\text { Café da manhã } \\
\text { americano } \\
\text { (pequeno-almoço } \\
\text { americano) }\end{array}$ & American Breakfast & Desayuno Americano \\
\hline Ammenities & $\begin{array}{c}\text { Kit de toalha e higiene } \\
\text { pessoal disponível nas } \\
\text { unidades habitacionais } \\
\text { (UHs). }\end{array}$ & $\begin{array}{l}\text { Kit de higiene } \\
\text { pessoal } \\
\text { (amenidades) }\end{array}$ & Ammenities & $\begin{array}{l}\text { Productos de higiene } \\
\text { personal }\end{array}$ \\
\hline Apart hotel & $\begin{array}{l}\text { Meio de hospedagem que } \\
\text { aceita hóspedes por } \\
\text { alguns dias com diária fixa. }\end{array}$ & Apart hotel & Apart hotel & Apart Hotel \\
\hline $\begin{array}{l}\text { Apartamento duplo } \\
\text { twin }\end{array}$ & $\begin{array}{c}\text { Termo que designa o } \\
\text { apartamento com duas } \\
\text { camas individuais. }\end{array}$ & Quarto duplo & Double room & Habitación doble \\
\hline Apartamento single & $\begin{array}{l}\text { Termo que designa o } \\
\text { apartamento com cama de } \\
\text { solteiro. }\end{array}$ & $\begin{array}{l}\text { Quarto simples ou } \\
\text { individual }\end{array}$ & Single room & $\begin{array}{l}\text { Habitación individual } \\
\text { o habitación sencilla }\end{array}$ \\
\hline $\begin{array}{l}\text { Apartamentos } \\
\text { comunicantes }\end{array}$ & $\begin{array}{l}\text { Unidades habitacionais } \\
\text { (UHs) conjuntas e com } \\
\text { ligação direta, não } \\
\text { separadas por porta de } \\
\text { comunicação. }\end{array}$ & $\begin{array}{l}\text { Apartamentos } \\
\text { comunicantes }\end{array}$ & $\begin{array}{l}\text { Connecting } \\
\text { apartments }\end{array}$ & $\begin{array}{l}\text { Habitaciones } \\
\text { comunicadas }\end{array}$ \\
\hline Aposento & $\begin{array}{c}\text { Termo que designa } \\
\text { qualquer tipo de } \\
\text { alojamento, ou seja, } \\
\text { moradia ou qualquer } \\
\text { unidade habitacional (UH). }\end{array}$ & Quarto & Room & Habitación \\
\hline Aviso de saída & $\begin{array}{l}\text { Impresso utilizado à saída } \\
\text { do hóspede, circulante por } \\
\text { vários setores do hotel } \\
\text { para conhecimento dos } \\
\text { funcionários. }\end{array}$ & Aviso de saída & Check-out notice & $\begin{array}{l}\text { Advertencia de } \\
\text { salida** }^{* *}\end{array}$ \\
\hline Baby Sitter & $\begin{array}{c}\text { Pessoa responsável por } \\
\text { cuidar das crianças, }\end{array}$ & Babá & Baby Sitter & Niñera \\
\hline
\end{tabular}




\begin{tabular}{|c|c|c|c|c|}
\hline & $\begin{array}{l}\text { conhecida como babá ou } \\
\text { cuidadora de crianças. }\end{array}$ & & & \\
\hline Back of the house & $\begin{array}{l}\text { Áreas não expostas ao } \\
\text { público, de circulação } \\
\text { restrita aos funcionários. }\end{array}$ & Áreas internas & Back of the house & Areas internas \\
\hline Balcony & $\begin{array}{l}\text { Apartamento ou suíte com } \\
\text { varanda. }\end{array}$ & $\begin{array}{c}\text { Quartos com } \\
\text { varanda }\end{array}$ & Balcony & $\begin{array}{c}\text { Habitación con } \\
\text { balcón }\end{array}$ \\
\hline Ballroom & $\begin{array}{l}\text { Designa o espaço de } \\
\text { entretenimento do hotel, } \\
\text { como o salão de festas. }\end{array}$ & Salão de festas & Ballroom & Salón de fiestas \\
\hline Bartender & $\begin{array}{l}\text { Profissional que prepara } \\
\text { drinks e coquetéis. }\end{array}$ & $\begin{array}{l}\text { Bartender/ } \\
\text { barman }\end{array}$ & Bartender & Bartender* \\
\hline Bassinet & $\begin{array}{l}\text { Berço pequeno e portátil } \\
\text { para bebês. }\end{array}$ & Berço pequeno & Bassinet & Cuna \\
\hline Bed \& breakfast & $\begin{array}{c}\text { Termo para designar que o } \\
\text { hóspede terá uma } \\
\text { pernoite com café. }\end{array}$ & Pernoite com café & Bed and breakfast & $\begin{array}{l}\text { Pernoche con } \\
\text { desayuno }\end{array}$ \\
\hline Bell Boy & Mensageiro do hotel. & Mensageiro & Bell boy & Mensajero \\
\hline Bell captain & Chefe dos mensageiros. & Chefe & Bell captain & Jefe de mensajeros \\
\hline Blanket & Cobertor. & Cobertor & Blanket & Frazada \\
\hline Blocked space & $\begin{array}{c}\text { Termo utilizado para } \\
\text { reservar espaços (assentos, } \\
\text { cabines ou quartos) para } \\
\text { grupos. }\end{array}$ & $\begin{array}{l}\text { Reservas para } \\
\text { grupo }\end{array}$ & Blocked space & $\begin{array}{l}\text { Reservado para } \\
\text { grupos }\end{array}$ \\
\hline Bloqueio & $\begin{array}{c}\text { Termo utilizado para } \\
\text { designar um quarto em } \\
\text { manutenção. }\end{array}$ & $\begin{array}{l}\text { Manutenção de } \\
\text { um quarto }\end{array}$ & $\begin{array}{l}\text { Blocked / } \\
\text { Out of Order }\end{array}$ & $\begin{array}{l}\text { Habitación en } \\
\text { Manutención }\end{array}$ \\
\hline Boleta & $\begin{array}{l}\text { Documento que deve ser } \\
\text { preenchido e assinado } \\
\text { pelo hóspede do hotel } \\
\text { quando feita a solicitação } \\
\text { de um serviço. }\end{array}$ & Bilhete & Ticket & Ticket \\
\hline Boletim de Caixa & Relatório do fluxo de caixa. & Relatório do caixa & Cash report & Flujo de caja \\
\hline Booking & Reserva. & Reserva & Booking & Reserva \\
\hline Booking lead time & $\begin{array}{c}\text { Tempo de espera para } \\
\text { uma reserva. }\end{array}$ & $\begin{array}{c}\text { Tempo de espera } \\
\text { para reserva }\end{array}$ & Booking lead time & $\begin{array}{l}\text { Reserva tiempo de } \\
\text { espera }\end{array}$ \\
\hline Brazilian Breakfast & $\begin{array}{l}\text { Café da manhã servido no } \\
\text { Brasil, incluindo produtos } \\
\text { genuinamente nacionais } \\
\text { como suco de acerola, } \\
\text { aipim, doce de abóbora, } \\
\text { bolo de fubá etc. }\end{array}$ & $\begin{array}{l}\text { Pequeno almoço } \\
\text { brasileiro } \\
\text { (sinônimo) }\end{array}$ & Brazilian Breakfast & Desayuno brasileño \\
\hline Breakfast & Café da manhã. & Café da manhã & Breakfast & Breakfast*/ Desayuno \\
\hline Brunch & $\begin{array}{l}\text { Café da manhã tardio e } \\
\text { reforçado. }\end{array}$ & $\begin{array}{l}\text { Café da manhã e } \\
\text { almoço }\end{array}$ & Brunch & Brunch* \\
\hline Budget & $\begin{array}{c}\text { Termo que designa um } \\
\text { tipo de planejamento } \\
\text { financeiro. }\end{array}$ & Plano de contas & Budget & Plan de cuentas \\
\hline Budget fare & $\begin{array}{l}\text { Tarifa na qual se aplica o } \\
\text { máximo de desconto } \\
\text { sobre os preços normais. }\end{array}$ & Tarifa de quebra & Budget fare & Rebajas totales \\
\hline Bundling & $\begin{array}{c}\text { Prática de combinar } \\
\text { produtos e serviços } \\
\text { diferentes para venda a } \\
\text { um preço único. }\end{array}$ & Pacote & Bundling & Paquete de ofertas \\
\hline
\end{tabular}




\begin{tabular}{|c|c|c|c|c|}
\hline By Night & Passeio noturno. & Passeio pela noite & By night & Paseo nocturno \\
\hline Cabana/Challet & $\begin{array}{l}\text { Apartamento separado do } \\
\text { hotel. }\end{array}$ & Cabana/Chalé & Challet & Cabaña \\
\hline Café Colonial & $\begin{array}{l}\text { Café reforçado, onde a } \\
\text { maioria dos produtos são } \\
\text { artesanais como: doces e } \\
\text { geleias caseiras, bolos, } \\
\text { pães variados, cuca, entre } \\
\text { outros. }\end{array}$ & Café colonial & $\begin{array}{l}\text { CountrysideStyle } \\
\text { Afternoon Coffee } \\
\text { with home-made } \\
\text { produce. Similar to } \\
\text { brunch. }\end{array}$ & Café Colonial \\
\hline Café continental & Café básico. & Café continental & $\begin{array}{c}\text { Continental } \\
\text { breakfast }\end{array}$ & Café Continental \\
\hline Camareira & $\begin{array}{c}\text { Arrumadeira de quartos de } \\
\text { hotéis ou de camarotes de } \\
\text { navios. }\end{array}$ & Camareira & Room maid & Mucama \\
\hline Camping & $\begin{array}{l}\text { Locais em que é possível } \\
\text { instalar barracas. }\end{array}$ & $\begin{array}{c}\text { Camping/ } \\
\text { Acampamento }\end{array}$ & Camping & Camping \\
\hline Cancellation Free & $\begin{array}{l}\text { Reserva cancelada } \\
\text { gratuitamente. }\end{array}$ & $\begin{array}{l}\text { Cancelamento } \\
\text { gratuito }\end{array}$ & Cancellation fee & Cancelación gratuita \\
\hline Cash & $\begin{array}{c}\text { Pagamento à vista em } \\
\text { dinheiro. }\end{array}$ & Dinheiro & Cash & Efectivo \\
\hline Cashier & $\begin{array}{l}\text { Caixa para pagamento no } \\
\text { balcão dos hotéis. }\end{array}$ & Caixa & Cashier & Caja \\
\hline CDL & $\begin{array}{c}\text { Reserva cancelada pelo } \\
\text { hóspede. }\end{array}$ & $\begin{array}{c}\text { Reserva } \\
\text { cancelada }\end{array}$ & Canceled Reversal & Reserva cancelada \\
\hline Check in & Horário de entrada. & Chegada ao hotel & Check in & Check in \\
\hline Check room & $\begin{array}{l}\text { Procedimento realizado } \\
\text { para conferência do } \\
\text { quarto do hotel, no } \\
\text { momento da saída do } \\
\text { hóspede. }\end{array}$ & $\begin{array}{c}\text { Conferência de } \\
\text { QH }\end{array}$ & Check room & Check room \\
\hline Check in time & $\begin{array}{l}\text { Nos hotéis, horário em que } \\
\text { um quarto estará } \\
\text { disponível; nos terminais } \\
\text { aéreos, o horário mais } \\
\text { tardio em que o } \\
\text { passageiro pode se } \\
\text { apresentar, sem o risco de } \\
\text { perder seu voo. }\end{array}$ & $\begin{array}{l}\text { Horário do check- } \\
\text { in }\end{array}$ & Check in time & $\begin{array}{l}\text { Horário de } \\
\text { Check in }\end{array}$ \\
\hline Check out & Horário de saída. & $\begin{array}{c}\text { Saída/ } \\
\text { Check out }\end{array}$ & Check out & Check out \\
\hline Check out Express & $\begin{array}{l}\text { Procedimento da recepção } \\
\text { onde o hóspede recebe } \\
\text { um extrato de sua conta } \\
\text { no dia anterior à data de } \\
\text { saída, efetua o pagamento } \\
\text { e fica isento da } \\
\text { necessidade de passar } \\
\text { novamente pela recepção. }\end{array}$ & Saída antecipada & $\begin{array}{l}\text { Check out } \\
\text { Express }\end{array}$ & Check out express \\
\hline Check out time & $\begin{array}{c}\text { O horário em que o } \\
\text { hóspede deve deixar o } \\
\text { hotel, para não pagar por } \\
\text { mais uma noite }\end{array}$ & $\begin{array}{l}\text { Horário do Check } \\
\text { out }\end{array}$ & Check out time & Horário de check out \\
\hline Children - CHD & $\begin{array}{c}\text { Termo utilizado para } \\
\text { denominar crianças entre } \\
12 \text { e } 13 \text { anos. } \\
\end{array}$ & Crianças & Children & Niños \\
\hline City Map & Mapa da cidade. & Mapa da cidade & City map & Mapa de la ciudad \\
\hline City Tour & $\begin{array}{l}\text { Passeio turístico pela } \\
\text { cidade. }\end{array}$ & Passeio turístico & City tour & Paseo turístico \\
\hline
\end{tabular}




\begin{tabular}{|c|c|c|c|c|}
\hline Clean Room & $\begin{array}{l}\text { Utilizado para identificar o } \\
\text { apartamento arrumado e } \\
\text { disponível para venda. }\end{array}$ & Quarto livre & Clean Room & Cuarto libre \\
\hline Closed dates & $\begin{array}{l}\text { Datas nas quais excursões } \\
\text { ou quartos de hotel não } \\
\text { estão disponíveis em } \\
\text { função de reservas ou } \\
\text { vendas efetuadas } \\
\text { anteriormente. }\end{array}$ & Datas fechadas & Closed dates & Fechas cerradas \\
\hline Coffee Break & $\begin{array}{c}\text { Intervalo das reuniões e } \\
\text { eventos onde é oferecido } \\
\text { no mínimo água. }\end{array}$ & Pausa para o café & Coffee Break & Coffee Break* \\
\hline Comanda & $\begin{array}{l}\text { Documento interno } \\
\text { utilizado pelo setor de } \\
\text { alimentos e bebidas para } \\
\text { registrar pedidos e vendas } \\
\text { para o cliente. }\end{array}$ & Comanda & $\begin{array}{l}\text { Card to register } \\
\text { goods consumed }\end{array}$ & Comanda \\
\hline Concierge & $\begin{array}{c}\text { Profissional que fica no } \\
\text { balcão na entrada do } \\
\text { hotel. }\end{array}$ & Porteiro & Concierge & Conserje \\
\hline Condotel & $\begin{array}{c}\text { Hotel de longa } \\
\text { permanência, onde os } \\
\text { condôminos podem morar } \\
\text { ou locar os apartamentos. }\end{array}$ & Condotel & Condotel & Condotel \\
\hline Conjugado & $\begin{array}{l}\text { Apartamentos um ao lado } \\
\text { do outro, ligados por uma } \\
\text { porta. }\end{array}$ & $\begin{array}{l}\text { Apartamentos } \\
\text { conjugados }\end{array}$ & $\begin{array}{l}\text { Adjoined } \\
\text { apartments }\end{array}$ & $\begin{array}{l}\text { Habitaciones } \\
\text { conjugadas }\end{array}$ \\
\hline Connecting rooms & Quartos conjugados. & $\begin{array}{c}\text { Quartos } \\
\text { conjugados }\end{array}$ & Connecting rooms & $\begin{array}{l}\text { Habitaciones } \\
\text { conectadas }\end{array}$ \\
\hline Continental Breakfast & Café da manhã simples. & $\begin{array}{l}\text { Café da manhã } \\
\text { simples }\end{array}$ & $\begin{array}{l}\text { Continental } \\
\text { Breakfast }\end{array}$ & $\begin{array}{l}\text { Desayuno } \\
\text { continental }\end{array}$ \\
\hline Continental Plan & $\begin{array}{l}\text { Diária de hotel que inclui } \\
\text { café da manhã } \\
\text { continental. }\end{array}$ & Plano continental & Continental plan & Plan de Continental \\
\hline Corporate rate & $\begin{array}{c}\text { Diária de hotel negociada } \\
\text { por uma empresa para o } \\
\text { uso de seus funcionários e } \\
\text { visitantes; tarifa concedida } \\
\text { por um hotel a todos os } \\
\text { executivos que viajam a } \\
\text { negócios. }\end{array}$ & Tarifa corporativa & Corporate rate & Tarifa corporativa \\
\hline Cortesia & $\begin{array}{l}\text { Oferecido pelo hotel como } \\
\text { isenção de uma conta. }\end{array}$ & Cortesia & Courtesy & Contusia/Cortesía \\
\hline Data Porta & Balcão da recepção. & Recepção & Reception Desk & Recepción \\
\hline Day rate & $\begin{array}{l}\text { Desfrutar durante um dia } \\
\text { as dependências do hotel. }\end{array}$ & Taxa de dia & Day rate & Tasa dia \\
\hline Day Use & $\begin{array}{l}\text { Utilizar o hotel de forma } \\
\text { particular sem } \\
\text { hospedagem, durante um } \\
\text { único dia. }\end{array}$ & Uso durante o dia & Day use & Para el uso diário \\
\hline Dead end booking & $\begin{array}{c}\text { Reserva finalizada em um } \\
\text { sistema de reserva, porém } \\
\text { nunca bilhetada. Esse tipo } \\
\text { de reserva pode acontecer } \\
\text { por falha de novos } \\
\text { funcionários, } \\
\text { esquecimento ou fraude } \\
\text { por parte do agente de } \\
\text { viagens. }\end{array}$ & Reserva final & Dead end booking & Reserva final \\
\hline
\end{tabular}




\begin{tabular}{|c|c|c|c|c|}
\hline Deadline & $\begin{array}{c}\text { Prazo final para } \\
\text { confirmação da reserva. }\end{array}$ & $\begin{array}{l}\text { Deadline ou prazo } \\
\text { final }\end{array}$ & Deadline & Fin del plazo \\
\hline Deposit Reservation & $\begin{array}{c}\text { Depósito correspondente } \\
\text { a uma diária que garante a } \\
\text { reserva. }\end{array}$ & $\begin{array}{l}\text { Depósito de } \\
\text { reserva }\end{array}$ & $\begin{array}{c}\text { Deposit } \\
\text { Reservation }\end{array}$ & Reserva de deposito \\
\hline Diária & $\begin{array}{l}\text { Utilizado para designar um } \\
\text { período pelo qual está } \\
\text { sendo feita a reserva ou } \\
\text { pagamento. Há variações: } \\
\text { em muitos hotéis, por } \\
\text { exemplo, as diárias } \\
\text { começam e terminam ao } \\
\text { meio dia; em outros às } 14 \\
\text { horas. }\end{array}$ & Diária & Daily rate & Diaria \\
\hline DNS (Did not Stay) & $\begin{array}{c}\text { Indica que o hóspede } \\
\text { partiu quase que } \\
\text { imediatamente depois de } \\
\text { seu registro. }\end{array}$ & Saída do hóspede & Did not stay & Salida del huesped \\
\hline Do Not Disturb & $\begin{array}{c}\text { Tarjeta colocada na porta } \\
\text { dos quartos, para indicar } \\
\text { que o hóspede não quer } \\
\text { ser perturbado. }\end{array}$ & $\begin{array}{c}\text { Aviso de } \\
\text { "não perturbe" }\end{array}$ & $\begin{array}{l}\text { Warming of } \\
\text { "Do not disturb" }\end{array}$ & $\begin{array}{l}\text { Aviso } \\
\text { "No molestar" }\end{array}$ \\
\hline Double (DBL) & $\begin{array}{c}\text { Apartamento para duas } \\
\text { pessoas, com uma cama } \\
\text { de casal ou duas de } \\
\text { solteiro. }\end{array}$ & Quarto duplo & Double room & Habitación doble \\
\hline Double booking & $\begin{array}{l}\text { Prática de reservar e } \\
\text { confirmar duas ou mais } \\
\text { reservas quando apenas } \\
\text { uma será utilizada. }\end{array}$ & Reserva dupla & Double booking & Reserva dupla \\
\hline Downgrade & $\begin{array}{c}\text { Disponibilização de um } \\
\text { apartamento de categoria } \\
\text { inferior à solicitada pelo } \\
\text { cliente. }\end{array}$ & Downgrade & Downgrade & Downgrade \\
\hline Early Check in & $\begin{array}{c}\text { Chegada antes da hora } \\
\text { permitida. }\end{array}$ & $\begin{array}{l}\text { Chegada mais } \\
\text { cedo }\end{array}$ & early arrival & Llegada anticipada \\
\hline Efficiency room & $\begin{array}{l}\text { Acomodação hoteleira } \\
\text { que dispõe de cozinha. }\end{array}$ & Efficiency room & Efficiency room & $\begin{array}{l}\text { Habitación com } \\
\text { cocina }\end{array}$ \\
\hline Emergency Door & $\begin{array}{c}\text { Saídas de emergência dos } \\
\text { hotéis. }\end{array}$ & $\begin{array}{c}\text { Saída de } \\
\text { emergência }\end{array}$ & Emergency Door & $\begin{array}{c}\text { Puerta de } \\
\text { emergencia }\end{array}$ \\
\hline English Breckfast & Café da manhã completo. & Café completo & English Breakfast & Desayuno completo \\
\hline Estacionalidade & $\begin{array}{c}\text { Prazo de uma localidade } \\
\text { turística. }\end{array}$ & Prazo de locação & Seasonality & Tiempo de reserva \\
\hline Estorno & $\begin{array}{l}\text { No contexto dos meios de } \\
\text { hospedagem, } \\
\text { estornar, significa tornar } \\
\text { sem efeito, anular um ato } \\
\text { anteriormente praticado. }\end{array}$ & Estorno & Reversal & Inversión \\
\hline European plan (EP) & $\begin{array}{c}\text { Tipo de diária sem } \\
\text { nenhum serviço de } \\
\text { alimentação, apenas } \\
\text { hospedagem. }\end{array}$ & $\begin{array}{l}\text { Hospedagem sem } \\
\text { diária }\end{array}$ & European plan & alojamiento sin diaria \\
\hline Extended stay room & $\begin{array}{c}\text { Apartamentos não } \\
\text { desocupados na data } \\
\text { prevista ou com reserva } \\
\text { estendida. } \\
\end{array}$ & $\begin{array}{l}\text { Estadia } \\
\text { prolongada }\end{array}$ & $\begin{array}{l}\text { Extended stay } \\
\text { room }\end{array}$ & Estadía prolongada \\
\hline Famtour & $\begin{array}{l}\text { Viagem de familiarização } \\
\text { para agentes de viagem. }\end{array}$ & $\begin{array}{c}\text { Viagem de } \\
\text { familiarização }\end{array}$ & Famtour & Famtour \\
\hline Fare Type & $\begin{array}{c}\text { Tipo de tarifa cobrada em } \\
\text { um flat. }\end{array}$ & Tarifa & Fare type & Tarifa \\
\hline
\end{tabular}




\begin{tabular}{|c|c|c|c|c|}
\hline Fitness Center & $\begin{array}{c}\text { Local do hotel onde ficam } \\
\text { a sauna, sala de ginástica, } \\
\text { massagem. }\end{array}$ & $\begin{array}{c}\text { Espaço de } \\
\text { entretenimento }\end{array}$ & Fitness center & Gimnasio \\
\hline Flat & $\begin{array}{c}\text { Estabelecimento que serve } \\
\text { a hóspedes de longa } \\
\text { permanência, que faz da } \\
\text { propriedade uma } \\
\text { residência. }\end{array}$ & Flat & Flat & Flat \\
\hline Flop House & $\begin{array}{c}\text { Designação para pensão } \\
\text { de baixo custo. }\end{array}$ & Pensão baixa & Flop house & Flop house \\
\hline Folder & $\begin{array}{l}\text { Pequeno encarte utilizado } \\
\text { como guia turístico. }\end{array}$ & Panfleto ou folder & Folder & Folder \\
\hline Forfait & $\begin{array}{l}\text { Pacote de serviços } \\
\text { personalizado. }\end{array}$ & Pacote & Package & Paquete \\
\hline Frequent lodger & $\begin{array}{l}\text { Hóspede que participa de } \\
\text { um programa de hóspede } \\
\text { frequente. }\end{array}$ & $\begin{array}{l}\text { Hóspede } \\
\text { frequente }\end{array}$ & Frequent lodger & Huésped frecuente \\
\hline Front Desk & $\begin{array}{c}\text { Balcão da recepção do } \\
\text { hotel. }\end{array}$ & Recepção & Front desk & Recepción \\
\hline Full Board (FAP) & $\begin{array}{c}\text { Pensão completa nos } \\
\text { meios de hospedagem ou } \\
\text { durante excursões. }\end{array}$ & $\begin{array}{l}\text { Pensão para } \\
\text { excursões }\end{array}$ & Full board & Pensión Completa \\
\hline Full day & $\begin{array}{c}\text { Tipo de hospedagem sem } \\
\text { pernoite, porém por mais } \\
\text { de sete horas. }\end{array}$ & $\begin{array}{l}\text { Hospedagem sem } \\
\text { pernoite }\end{array}$ & Full day & $\begin{array}{l}\text { Hospedaje sin } \\
\text { pernoche }\end{array}$ \\
\hline Full Fare & Tarifa sem descontos. & Tarifa cheia & Full fare & $\begin{array}{c}\text { Tarifa completa o } \\
\text { tarifa plena }\end{array}$ \\
\hline Fully Booked & Hotel totalmente lotado. & $\begin{array}{c}\text { Totalmente } \\
\text { reservado }\end{array}$ & Fully booked & $\begin{array}{c}\text { Completamente } \\
\text { Ileno }\end{array}$ \\
\hline Garantia de No show & $\begin{array}{l}\text { Pagamento da primeira } \\
\text { diária do período } \\
\text { reservado não utilizado. }\end{array}$ & $\begin{array}{l}\text { Primeiro } \\
\text { pagamento } \\
\text { garantido }\end{array}$ & $\begin{array}{l}\text { No show } \\
\text { Guarantee }\end{array}$ & $\begin{array}{l}\text { Garantía de } \\
\text { No show }\end{array}$ \\
\hline Governanta & $\begin{array}{c}\text { A encarregada da } \\
\text { organização dos serviços } \\
\text { de manutenção e limpeza } \\
\text { dos aposentos. }\end{array}$ & Governanta & Housekeeper & Ama de llaves \\
\hline $\begin{array}{l}\text { Guaranteed } \\
\text { reservation }\end{array}$ & $\begin{array}{l}\text { Reserva mantida por toda } \\
\text { noite, independente do } \\
\text { grupo chegar ou não a } \\
\text { tempo. Geralmente o } \\
\text { comprador, paga por este } \\
\text { privilégio, garantindo o } \\
\text { pagamento, seja a reserva } \\
\text { usada ou não. }\end{array}$ & Reserva garantida & $\begin{array}{l}\text { Guaranteed } \\
\text { reservation }\end{array}$ & Reserva garantizada \\
\hline Guest Charge & $\begin{array}{c}\text { Especifica as diversas } \\
\text { despesas dos hóspedes, } \\
\text { tais como frigobar, } \\
\text { lavanderia, restaurante } \\
\text { etc. }\end{array}$ & Consumação & Guest Charge & Consumación \\
\hline Guest Relations & $\begin{array}{c}\text { Funcionário responsável } \\
\text { pelo atendimento dos } \\
\text { hóspedes, informando-os } \\
\text { sobre o hotel e a cidade e } \\
\text { se colocando à disposição } \\
\text { para resolver eventuais } \\
\text { problemas. }\end{array}$ & $\begin{array}{l}\text { Recepcionista } \\
\text { responsável pelos } \\
\text { hóspedes }\end{array}$ & Guest Relations & $\begin{array}{c}\text { Relaciones Con Los } \\
\text { Huéspedes }\end{array}$ \\
\hline Guest services & $\begin{array}{l}\text { Departamento que } \\
\text { concentra as informações, } \\
\text { solicitações e administra } \\
\text { reclamações dos } \\
\text { hóspedes. }\end{array}$ & $\begin{array}{l}\text { Serviço para os } \\
\text { hóspedes }\end{array}$ & Guest services & $\begin{array}{l}\text { Servicios para } \\
\text { huéspedes }\end{array}$ \\
\hline
\end{tabular}




\begin{tabular}{|c|c|c|c|c|}
\hline Habituê & $\begin{array}{l}\text { Hóspede frequente no } \\
\text { meio de hospedagem. }\end{array}$ & $\begin{array}{c}\text { Frequentador } \\
\text { habitual }\end{array}$ & $\begin{array}{l}\text { Frequent } \\
\text { Guest }\end{array}$ & Huésped habitual \\
\hline Half Board (MAP) & $\begin{array}{l}\text { Meia pensão, ou seja, café } \\
\text { da manhã, mais almoço ou } \\
\text { jantar. }\end{array}$ & Meia pensão & Half board & Media pensión \\
\hline Hall Lobby & $\begin{array}{c}\text { Área de entrada e estar de } \\
\text { um hotel. }\end{array}$ & Salão do átrio & Hall lobby & Vestíbulo del Salón \\
\hline Handicapped Room & $\begin{array}{l}\text { Unidade habitacional (UH) } \\
\text { adaptada e preparada } \\
\text { para hóspedes com } \\
\text { necessidades especiais. }\end{array}$ & $\begin{array}{c}\text { Quarto para } \\
\text { deficientes físicos }\end{array}$ & $\begin{array}{l}\text { Handicapp-ed } \\
\text { Room }\end{array}$ & $\begin{array}{l}\text { Habitaciones para } \\
\text { deficientes físicos }\end{array}$ \\
\hline Held luggage & $\begin{array}{l}\text { Procedimento efetuado } \\
\text { para retirada de bagagens } \\
\text { por falta de pagamento } \\
\text { por parte do hóspede. }\end{array}$ & $\begin{array}{c}\text { Retirada de } \\
\text { bagagens }\end{array}$ & Held luggage & Held luggage \\
\hline Hold time & $\begin{array}{l}\text { Horário em que os quartos } \\
\text { reservados, mas não } \\
\text { garantidos são liberados } \\
\text { para novas reservas. }\end{array}$ & Tempo de espera & Hold time & Hora de espera \\
\hline Holiday & $\begin{array}{c}\text { Termo utilizado em } \\
\text { turismo e hotelaria que } \\
\text { significa férias ou feriado. }\end{array}$ & Feriado & Holiday & Feriado \\
\hline Home Exchange & $\begin{array}{l}\text { Pessoas que permutam } \\
\text { suas residências em } \\
\text { diferentes cidades ou } \\
\text { países, como estratégia } \\
\text { para reduzir os custos de } \\
\text { suas viagens de férias. }\end{array}$ & Troca de casas & Home Exchange & Intercambio de casas \\
\hline Hospitality industry & $\begin{array}{l}\text { Termo aplicado à indústria } \\
\text { de hotéis, restaurantes, } \\
\text { resorts e entretenimento. }\end{array}$ & $\begin{array}{l}\text { Indústria da } \\
\text { hospitalidade }\end{array}$ & Hospitality industry & $\begin{array}{l}\text { Industria de la } \\
\text { hospitalidad }\end{array}$ \\
\hline Hosted tour & $\begin{array}{c}\text { Excursão que inclui os } \\
\text { serviços de uma pessoa, } \\
\text { que fica à disposição dos } \\
\text { passageiros para atendê- } \\
\text { los. }\end{array}$ & Hosted tour & Hosted tour & Guía Individual \\
\hline Hostel & $\begin{array}{l}\text { Unidade hoteleira com } \\
\text { tarifas moderadas, mais } \\
\text { utilizadas por jovens } \\
\text { (também conhecida como } \\
\text { albergue da juventude). }\end{array}$ & Albergue & Hostel & Albergue \\
\hline Hotel Charme & $\begin{array}{l}\text { Hotéis localizados em } \\
\text { prédios históricos. }\end{array}$ & Hotel charme & $\begin{array}{l}\text { Boutique Hotel/ } \\
\text { Charm Hotel }\end{array}$ & Hotel charm \\
\hline Hotel de Lazer & $\begin{array}{c}\text { Hotel voltado } \\
\text { especialmente para } \\
\text { atividades de lazer e } \\
\text { entretenimento dos } \\
\text { hóspedes. } \\
\end{array}$ & Hotel de lazer & Leisure hotel & Hotel tiempo de ocio \\
\hline Hotelier & $\begin{array}{c}\text { Este termo é direcionado } \\
\text { ao sócio ou proprietário } \\
\text { do hotel. }\end{array}$ & Hoteleiro & Hotelier & Hotelero \\
\hline Housekeeping & $\begin{array}{l}\text { Departamento de hotel } \\
\text { responsável pela limpeza e } \\
\text { manutenção dos } \\
\text { apartamentos e áreas } \\
\text { públicas. }\end{array}$ & $\begin{array}{l}\text { Serviço de } \\
\text { limpeza }\end{array}$ & Housekeeping & Servicio de limpieza \\
\hline In house & $\begin{array}{l}\text { Identifica o hóspede que } \\
\text { está com registro de } \\
\text { hospedagem no sistema. }\end{array}$ & $\begin{array}{c}\text { Registro de } \\
\text { hospedagem }\end{array}$ & In house & In house \\
\hline Independent hotel & $\begin{array}{l}\text { Hotel independente, que } \\
\text { não tem contrato com } \\
\text { qualquer cadeia hoteleira. }\end{array}$ & $\begin{array}{c}\text { Hotel } \\
\text { independente }\end{array}$ & Independent hotel & Hotel independiente \\
\hline
\end{tabular}




\begin{tabular}{|c|c|c|c|c|}
\hline Infant & $\begin{array}{c}\text { Termo utilizado para } \\
\text { designar bebês de } 0 \text { até } 2 \\
\text { anos, nas dependências } \\
\text { do hotel. }\end{array}$ & Criança & Infant & Niño \\
\hline Information Desk & $\begin{array}{l}\text { Local onde os hóspedes } \\
\text { tiram suas dúvidas; termo } \\
\text { que designa o ponto de } \\
\text { informação turística. }\end{array}$ & $\begin{array}{l}\text { Balcão De } \\
\text { Informações }\end{array}$ & Information Desk & Mesa De Información \\
\hline Inside room & $\begin{array}{l}\text { Indica os apartamentos } \\
\text { internos de um hotel. }\end{array}$ & $\begin{array}{l}\text { Apartamentos } \\
\text { internos }\end{array}$ & Inside room & $\begin{array}{l}\text { Dentro de la } \\
\text { habitación }\end{array}$ \\
\hline Invoice & $\begin{array}{c}\text { Termo que designa a } \\
\text { fatura comercial do hotel. }\end{array}$ & Fatura & Invoice & Factura \\
\hline Jet Leg & $\begin{array}{l}\text { Desajuste do relógio } \\
\text { biológico ocasionado pela } \\
\text { troca de fuso horário em } \\
\text { viagens - podendo causar } \\
\text { mal-estar. }\end{array}$ & Jet Leg & Jet Leg & Jet Leg \\
\hline Junior Suite & $\begin{array}{l}\text { Quartos espaçosos, com } \\
\text { separação entre o quarto e } \\
\text { sala de estar. }\end{array}$ & $\begin{array}{l}\text { Quartos } \\
\text { espaçosos }\end{array}$ & Junior Suite & Amplias habitaciones \\
\hline Key Pass & $\begin{array}{l}\text { Envelope onde se coloca a } \\
\text { chave das dependências } \\
\text { do hotel. }\end{array}$ & Chave passe & Key pass & Pase Key \\
\hline King Size Bed & $\begin{array}{c}\text { Termo designado para o } \\
\text { hóspede identificar que } \\
\text { aquele quarto tem cama } \\
\text { de casal. }\end{array}$ & Cama king & king size bed & Cama king Size \\
\hline Kitchenette & $\begin{array}{l}\text { Pequeno apartamento de } \\
\text { sala e cozinha. }\end{array}$ & Kitinete & kitchenette & Loft con cocina \\
\hline Late booking service & $\begin{array}{l}\text { Nome dado ao serviço de } \\
\text { reservas de última hora. }\end{array}$ & $\begin{array}{l}\text { Serviço de reserva } \\
\text { tardia }\end{array}$ & $\begin{array}{l}\text { Late booking } \\
\text { service }\end{array}$ & $\begin{array}{l}\text { Servicio de reserva } \\
\text { de última hora }\end{array}$ \\
\hline Late Check-out & $\begin{array}{c}\text { Saída do hospede após a } \\
\text { diária. }\end{array}$ & Check out tardio & late check out & $\begin{array}{l}\text { Check out tarde o } \\
\text { salida tardia** }\end{array}$ \\
\hline Lay over & $\begin{array}{c}\text { Acomodação especial } \\
\text { utilizada em imprevistos } \\
\text { (problemas técnicos, } \\
\text { atrasos). }\end{array}$ & Escala & Lay over & Layover \\
\hline Limited Service & $\begin{array}{l}\text { Serviço limitado oferecido } \\
\text { por hotéis com alguns } \\
\text { pequenos serviços além } \\
\text { da hospedagem. }\end{array}$ & Serviço limitado & Limited Service & Servicio limitado \\
\hline Lista de Espera & $\begin{array}{l}\text { Lista de espera dos } \\
\text { hóspedes do hotel. }\end{array}$ & Lista de espera & Wait list & Lista de espera \\
\hline Lista negra & $\begin{array}{c}\text { Lista de hóspedes } \\
\text { indesejáveis do hotel. }\end{array}$ & $\begin{array}{c}\text { Hóspedes } \\
\text { indesejáveis }\end{array}$ & Black list & Lista negra \\
\hline Lobby & $\begin{array}{l}\text { No ramo hoteleiro é } \\
\text { designado como a sala de } \\
\text { espera de um hotel. }\end{array}$ & Lobby & Lobby & Vestuario \\
\hline Lodging House & $\begin{array}{c}\text { Termo que designa } \\
\text { alojamentos e pousadas. }\end{array}$ & Alojamentos & Lodging house & Lodging house \\
\hline Long stay & $\begin{array}{c}\text { Quando o hotel é utilizado } \\
\text { por um longo período de } \\
\text { hospedagem. }\end{array}$ & $\begin{array}{l}\text { Longa } \\
\text { permanência }\end{array}$ & Long stay & Estadía larga \\
\hline Lost and Found & $\begin{array}{l}\text { Local onde ficam os } \\
\text { pertences perdidos ou } \\
\text { esquecidos pelos } \\
\text { hóspedes, departamento } \\
\text { de achados e perdidos. }\end{array}$ & $\begin{array}{l}\text { Achados e } \\
\text { perdidos }\end{array}$ & Lost and found & $\begin{array}{l}\text { Olvidados y } \\
\text { Encontrados }\end{array}$ \\
\hline Lost Baggage & $\begin{array}{c}\text { Termo que designa } \\
\text { quando alguma bagagem } \\
\text { é extraviada. }\end{array}$ & $\begin{array}{l}\text { Bagagem } \\
\text { extraviada }\end{array}$ & Lost baggage & Equipaje perdido \\
\hline
\end{tabular}




\begin{tabular}{|c|c|c|c|c|}
\hline Lounge & $\begin{array}{c}\text { No ramo hoteleiro é } \\
\text { designado como sala de } \\
\text { estar. }\end{array}$ & $\begin{array}{l}\text { Lounge ou } \\
\text { sala de espera }\end{array}$ & Lounge & $\begin{array}{l}\text { Lounge ou } \\
\text { sala de espera }\end{array}$ \\
\hline Low Season & $\begin{array}{c}\text { Termo que designa a baixa } \\
\text { estação/temporada nos } \\
\text { hotéis. }\end{array}$ & Baixa temporada & Low Season & Temporada baja \\
\hline Luxe & $\begin{array}{l}\text { Termo que designa hotel } \\
\text { cinco estrelas, ou seja, } \\
\text { hotéis de alta qualidade. }\end{array}$ & Luxo & Luxe & Lujo \\
\hline $\begin{array}{l}\text { Maleteiro - } \\
\text { Mensageiro }\end{array}$ & $\begin{array}{c}\text { Funcionário encarregado } \\
\text { de levar as malas dos } \\
\text { hóspedes. }\end{array}$ & Mensageiro & Messenger & Mensajero \\
\hline Meeting facilities & $\begin{array}{c}\text { Instalações e } \\
\text { equipamentos existentes } \\
\text { no hotel para } \\
\text { atendimentos de eventos, } \\
\text { convenções e reuniões. }\end{array}$ & $\begin{array}{l}\text { Instalações para } \\
\text { encontro }\end{array}$ & Meeting facilities & $\begin{array}{l}\text { Intalaciones para } \\
\text { eventos }\end{array}$ \\
\hline Meia Pensão & $\begin{array}{c}\text { Hospedagem com diárias } \\
\text { que incluem duas } \\
\text { refeições. }\end{array}$ & Meia-pensão & Half board & Media pensión \\
\hline Mensalista & $\begin{array}{c}\text { Hóspede com } \\
\text { permanência mínima de } \\
\text { trinta dias. }\end{array}$ & Mensalista & Salaried & Huésped mensalista \\
\hline Motel & $\begin{array}{c}\text { Estabelecimento } \\
\text { localizado na beira das } \\
\text { estradas de grande } \\
\text { movimento como as } \\
\text { rodovias, que aluga } \\
\text { quartos ou apartamentos } \\
\text { para pernoite ou por hora. }\end{array}$ & Motel & Motel & Motel \\
\hline Night Bird & $\begin{array}{l}\text { Profissionais do sexo que } \\
\text { atendem solicitações dos } \\
\text { hóspedes. }\end{array}$ & $\begin{array}{l}\text { Profissionais } \\
\text { do sexo }\end{array}$ & Night bird & $\begin{array}{l}\text { Profesionales } \\
\text { del sexo }\end{array}$ \\
\hline No Show & $\begin{array}{c}\text { Termo que designa o não } \\
\text { comparecimento do } \\
\text { hóspede na data. }\end{array}$ & No show & No show & No show \\
\hline On Duty & $\begin{array}{c}\text { Serviço de plantão do } \\
\text { hotel. }\end{array}$ & Plantão do hotel & On duty & De guardia \\
\hline Outsourcing & $\begin{array}{l}\text { Subcontratação de } \\
\text { serviços para o hotel. }\end{array}$ & $\begin{array}{l}\text { Terceirização de } \\
\text { serviços }\end{array}$ & Outsourcing & Externalización \\
\hline Overbooking & $\begin{array}{l}\text { Reservas feitas além da } \\
\text { capacidade de } \\
\text { hospedagem. }\end{array}$ & Overbooking & Overbooking & Overbooking \\
\hline Pacote Turístico & $\begin{array}{l}\text { Conjunto de serviços } \\
\text { turísticos vendidos como } \\
\text { um todo, em que } \\
\text { tipicamente incluem } \\
\text { viagem, transfers, } \\
\text { alojamento e excursões. }\end{array}$ & Pacote turístico & Package & Paquete turístico \\
\hline Pax & $\begin{array}{l}\text { Termo utilizado no ramo } \\
\text { turístico para indicar o } \\
\text { passageiro, o hóspede, o } \\
\text { cliente. Pax significa } \\
\text { pessoas. }\end{array}$ & Pax & Pax & Pax \\
\hline Pensão & $\begin{array}{l}\text { Hospedaria ou hotel que } \\
\text { abriga hóspedes } \\
\text { provisórios ou } \\
\text { permanentes. }\end{array}$ & Pensão & Half board basis & Pensión \\
\hline Pensão Completa & $\begin{array}{l}\text { Hospedagem com diárias } \\
\text { que incluem três ou mais } \\
\text { refeições. }\end{array}$ & Pensão completa & Full board basis & Pensión completa \\
\hline Penthouse & $\begin{array}{l}\text { Suíte no andar mais } \\
\text { elevado do hotel. }\end{array}$ & Penthouse & Penthouse & Penthause \\
\hline
\end{tabular}




\begin{tabular}{|c|c|c|c|c|}
\hline Pernoite & $\begin{array}{l}\text { Hospedagem apenas para } \\
\text { passar a noite. }\end{array}$ & Pernoite & Overnight stay & Pasar la noche \\
\hline Pillow & $\begin{array}{c}\text { Travesseiro do quarto } \\
\text { hotel. }\end{array}$ & Travesseiro & Pillow & Almohada \\
\hline Pillow case & $\begin{array}{c}\text { Fronha do travesseiro do } \\
\text { quarto de hotel. }\end{array}$ & Fronha & Pillow case & Funda de almohada \\
\hline Pool & $\begin{array}{l}\text { Proprietário disponibiliza } \\
\text { seu flat, para locação em } \\
\text { conjunto com uma } \\
\text { empresa de administração } \\
\text { hoteleira, como se fosse } \\
\text { um apartamento de hotel. }\end{array}$ & Pool & Pool & Pool \\
\hline Porter & $\begin{array}{l}\text { Termo que designa o } \\
\text { funcionário responsável } \\
\text { por carregar bagagem. }\end{array}$ & Porteiro & Porter & Portero \\
\hline Quádruplo (QDP) & $\begin{array}{c}\text { Apartamentos para quatro } \\
\text { pessoas. }\end{array}$ & Quádruplo & Quadruple & $\begin{array}{c}\text { Habitaciones } \\
\text { cuadruples }\end{array}$ \\
\hline Queen Size Bed & $\begin{array}{c}\text { Cama de casal tamanho } \\
1,98 \mathrm{~m} \times 1,58 \mathrm{~m} .\end{array}$ & Cama queen & Queen size bed & Size \\
\hline Rack Rate & $\begin{array}{c}\text { Tarifa balcão aplicada para } \\
\text { hóspedes que não têm } \\
\text { reserva e se apresentam } \\
\text { no hotel. }\end{array}$ & Tarifa balcão & Rack rate & Tarifa rack \\
\hline Reserva de Grupos & $\begin{array}{l}\text { Termo que designa uma } \\
\text { reserva para um grupo de } \\
\text { pessoas no hotel. }\end{array}$ & $\begin{array}{l}\text { Reserva de } \\
\text { grupos }\end{array}$ & Group reservation & Reserva de grupos \\
\hline Resort & $\begin{array}{l}\text { Hotel de lazer, localizado } \\
\text { fora dos centros urbanos } \\
\text { com áreas próprias para a } \\
\text { prática de esportes ou } \\
\text { algum tipo de atividade } \\
\text { para os hóspedes. }\end{array}$ & Resort & Resort & Resort \\
\hline $\begin{array}{l}\text { Revenda de } \\
\text { Hospedagem }\end{array}$ & $\begin{array}{l}\text { Quando o hotel permite } \\
\text { que um cliente contrate } \\
\text { um plano de hospedagem } \\
\text { e revenda para outro. }\end{array}$ & $\begin{array}{l}\text { Revenda de } \\
\text { hospedagem }\end{array}$ & Hosting Reseller & Hosting Reseller \\
\hline $\begin{array}{l}\text { Revpar (Revenue per } \\
\text { available room) }\end{array}$ & $\begin{array}{l}\text { Representa a relação de } \\
\text { receita de hospedagem } \\
\text { pelo número de unidades } \\
\text { habitacionais (UHS) } \\
\text { disponíveis. }\end{array}$ & Revpar & $\begin{array}{l}\text { Revenue per } \\
\text { available } \\
\text { room }\end{array}$ & $\begin{array}{l}\text { Ingresos por } \\
\text { habitación } \\
\text { disponible }\end{array}$ \\
\hline Room & $\begin{array}{l}\text { Na linha hoteleira é o } \\
\text { termo que designa quarto. }\end{array}$ & Quarto & Room & Habitación \\
\hline Room Clerck & $\begin{array}{c}\text { Encarregado de registrar e } \\
\text { distribuir as chaves dos } \\
\text { quartos aos hóspedes do } \\
\text { hotel. }\end{array}$ & Recepcionista & Room clerck & Recepcionista \\
\hline Room Linen & $\begin{array}{c}\text { Roupas de cama de um } \\
\text { hotel. }\end{array}$ & Roupa de cama & Room linen & Ropas de cama \\
\hline Room Maid & Camareira de hotel. & Serviço de quarto & Room maid & Cuarto de servicio \\
\hline Room Night & $\begin{array}{c}\text { Termo na qual designa } \\
\text { que o hóspede terá } \\
\text { apenas uma pernoite no } \\
\text { hotel. } \\
\end{array}$ & Pernoite & Room night & Room night \\
\hline Room number & $\begin{array}{l}\text { Número de quarto do } \\
\text { hotel. }\end{array}$ & $\begin{array}{l}\text { Número de } \\
\text { quartos }\end{array}$ & Room number & $\begin{array}{l}\text { Número de } \\
\text { habitaciones }\end{array}$ \\
\hline Rooming List & $\begin{array}{l}\text { Relação com o nome dos } \\
\text { hóspedes. }\end{array}$ & $\begin{array}{l}\text { Lista dos } \\
\text { hóspedes }\end{array}$ & Rooming list & $\begin{array}{l}\text { Relación de } \\
\text { huéspedes }\end{array}$ \\
\hline Room-mate & Companheiro de quarto. & $\begin{array}{c}\text { Companheiro de } \\
\text { quarto }\end{array}$ & Room mate & $\begin{array}{l}\text { Compañera de } \\
\text { cuarto }\end{array}$ \\
\hline
\end{tabular}




\begin{tabular}{|c|c|c|c|c|}
\hline Round Trip & $\begin{array}{l}\text { Viagem de ida e volta } \\
\text { entre lugares } \\
\text { relativamente próximos. }\end{array}$ & Bate volta & Round Trip & Paseos cercanos \\
\hline Run of the House & $\begin{array}{c}\text { Termo utilizado para } \\
\text { designar o último } \\
\text { apartamento disponível, } \\
\text { independentemente da } \\
\text { categoria. } \\
\end{array}$ & $\begin{array}{l}\text { Último } \\
\text { apartamento } \\
\text { disponível }\end{array}$ & Run of the house & $\begin{array}{l}\text { Última habitación } \\
\text { disponible }\end{array}$ \\
\hline Safety Box & Cofre do hotel. & Cofre & Safety box & Cofre \\
\hline Semana & $\begin{array}{l}\text { Diária estipulada por } \\
\text { semana, utilizada em } \\
\text { estabelecimentos de } \\
\text { hospedagem que abrigam } \\
\text { hóspedes por períodos } \\
\text { semanais (comum em } \\
\text { apart-hotéis). }\end{array}$ & Semana & Week & Semana \\
\hline Sightseeing & $\begin{array}{l}\text { Acomodação de casal na } \\
\text { hotelaria. }\end{array}$ & $\begin{array}{l}\text { Acomodação em } \\
\text { pontos turísticos }\end{array}$ & Sightseeing & $\begin{array}{l}\text { Habitación para } \\
\text { parejas }\end{array}$ \\
\hline Single Room & $\begin{array}{l}\text { Apartamento simples para } \\
\text { somente um hóspede. }\end{array}$ & Quarto de solteiro & Single room & Habitación individual \\
\hline Site & $\begin{array}{l}\text { Quando um funcionário } \\
\text { leva um hóspede para } \\
\text { conhecer o hotel. }\end{array}$ & $\begin{array}{c}\text { Local para } \\
\text { conhecimento do } \\
\text { hotel }\end{array}$ & Site & Conocer el sitio \\
\hline Ski-in & $\begin{array}{l}\text { Hotel de montanha onde } \\
\text { o hóspede pode } \\
\text { sair/chegar esquiando. }\end{array}$ & Esquiar & Ski-in & Ski-in \\
\hline Skipper & $\begin{array}{l}\text { Hóspede que sai do hotel } \\
\text { sem pagar a conta. }\end{array}$ & $\begin{array}{c}\text { Hóspede } \\
\text { inadimplente }\end{array}$ & Skipper & Skipper \\
\hline Slip de reserva & $\begin{array}{c}\text { Cadastro de reserva do } \\
\text { hotel. }\end{array}$ & $\begin{array}{l}\text { Cadastro de } \\
\text { reserva }\end{array}$ & Slip & Registro de Reservas \\
\hline Smoking Room & $\begin{array}{l}\text { Sala reservadas para } \\
\text { fumantes. }\end{array}$ & $\begin{array}{l}\text { Local direcionado } \\
\text { para fumantes }\end{array}$ & Smoking Room & Sala de fumadores \\
\hline Sold Out & $\begin{array}{c}\text { Hotel totalmente } \\
\text { reservado/esgotado. }\end{array}$ & Esgotado & Sold out & Agotado \\
\hline Stand By & $\begin{array}{c}\text { Reserva em espera da } \\
\text { confirmação do hóspede. }\end{array}$ & $\begin{array}{c}\text { Reserva em } \\
\text { espera }\end{array}$ & Stand by & En espera \\
\hline Standard (STD) & $\begin{array}{l}\text { Designa o tipo de unidade } \\
\text { habitacional (UH); um } \\
\text { apartamento padrão é o } \\
\text { mais pedido pelos } \\
\text { hóspedes. }\end{array}$ & $\begin{array}{l}\text { Apartamento } \\
\text { padrão }\end{array}$ & Standard & Standard \\
\hline Star Rating System & $\begin{array}{l}\text { Sistema que classifica os } \\
\text { hotéis por estrelas. }\end{array}$ & $\begin{array}{c}\text { Hotéis } \\
\text { classificados com } \\
\text { estrelas }\end{array}$ & Star Rating System & $\begin{array}{l}\text { Hoteles classificados } \\
\text { por estellas }\end{array}$ \\
\hline Stay over & $\begin{array}{l}\text { Hóspede que permanece } \\
\text { no hotel além do previsto. }\end{array}$ & $\begin{array}{l}\text { Prolongamento } \\
\text { de estadia do } \\
\text { hóspede }\end{array}$ & Stay over & Stay over \\
\hline Studio & $\begin{array}{l}\text { Apartamento com um sofá } \\
\text { cama. }\end{array}$ & $\begin{array}{l}\text { UHs com sofá } \\
\text { cama }\end{array}$ & Studio & Studio \\
\hline Suitcase & $\begin{array}{l}\text { Mala de viagem do } \\
\text { hóspede. }\end{array}$ & Mala & Suitcase & Valija \\
\hline Supereconômicos & $\begin{array}{l}\text { Hotéis sem nenhum } \\
\text { serviço diferenciado, } \\
\text { apenas a hospedagem. }\end{array}$ & $\begin{array}{c}\text { Hotéis } \\
\text { econômicos }\end{array}$ & Super economic & Hoteles economicos \\
\hline Taxa de Ocupação & $\begin{array}{l}\text { Índice de produtividade } \\
\text { de um hotel. }\end{array}$ & Taxa de ocupação & Occupancy rate & Tasa de ocupación \\
\hline Taxa de Serviço & $\begin{array}{l}\text { Taxa cobrada por algum } \\
\text { serviço prestado pelo } \\
\text { hotel. }\end{array}$ & Taxa de serviço & Fare & Cargo por servicio \\
\hline
\end{tabular}




\begin{tabular}{|c|c|c|c|c|}
\hline Time Share & $\begin{array}{l}\text { Aquisição de uma ou mais } \\
\text { semanas de hospedagem } \\
\text { em um apartamento. }\end{array}$ & $\begin{array}{l}\text { Uma ou mais } \\
\text { semanas de } \\
\text { aquisição do } \\
\text { apartamento }\end{array}$ & Time share & $\begin{array}{l}\text { Más tempo de } \\
\text { alquiler }\end{array}$ \\
\hline Transfer In & $\begin{array}{l}\text { Transferência do pax do } \\
\text { aeroporto ao hotel. }\end{array}$ & $\begin{array}{l}\text { Transferência } \\
\text { para o hotel }\end{array}$ & Transfer In & Transferencia al hotel \\
\hline Transfer Out & $\begin{array}{l}\text { Transferência do pax do } \\
\text { hotel ao aeroporto. }\end{array}$ & $\begin{array}{c}\text { Transferência } \\
\text { para fora do hotel }\end{array}$ & Transfer Out & Transferência a cabo \\
\hline Transfer & $\begin{array}{c}\text { Viagem de um aeroporto } \\
\text { ao hotel. }\end{array}$ & Translado & Transfer & Traslado \\
\hline Turn down & Abertura de cama. & Abertura de cama & Turn down & Rechazar \\
\hline Upgrade & $\begin{array}{l}\text { Transferência de classe } \\
\text { inferior para uma superior } \\
\text { sem cobrança adicional. }\end{array}$ & Upgrade & Upgrade & Up grade \\
\hline Urgent Service & $\begin{array}{c}\text { Serviço urgente para lavar } \\
\text { as roupas dos hóspedes } \\
\text { dos hotéis. }\end{array}$ & Serviço urgente & Urgent service & Servicio urgente \\
\hline Vacant and Ready & $\begin{array}{l}\text { Quarto vazio e pronto para } \\
\text { ocupação. }\end{array}$ & Quarto disponível & Vacant and ready & $\begin{array}{l}\text { Habitación } \\
\text { disponible }\end{array}$ \\
\hline Valet Parking & $\begin{array}{l}\text { Estacionamento com } \\
\text { manobrista. }\end{array}$ & Manobrista & Valet parking & $\begin{array}{c}\text { Chofer de } \\
\text { estacionamiento }\end{array}$ \\
\hline Valet Service & $\begin{array}{l}\text { Serviço de lavanderia nos } \\
\text { quartos de hotéis. }\end{array}$ & Valet service & Valet service & Valet service \\
\hline Vip & Hóspede especial. & Hóspede vip & Vip & Vip \\
\hline Voucher & $\begin{array}{c}\text { Documento que } \\
\text { comprova o pagamento } \\
\text { da reserva. }\end{array}$ & $\begin{array}{l}\text { Comprovante de } \\
\text { reserva }\end{array}$ & Voucher & $\begin{array}{l}\text { Voucher o } \\
\text { confirmación de } \\
\text { reserva }\end{array}$ \\
\hline Walk in & $\begin{array}{c}\text { Pessoa que chega a um } \\
\text { hotel sem ter feito reserva. }\end{array}$ & $\begin{array}{l}\text { Pessoa sem } \\
\text { reserva }\end{array}$ & walk in guest & Walk in \\
\hline Wake up call & $\begin{array}{c}\text { Despertador do hóspede, } \\
\text { para não fazê-lo perder a } \\
\text { hora de seus } \\
\text { compromissos. }\end{array}$ & Despertador & Wake up call & Despertador \\
\hline Welcome drink & $\begin{array}{l}\text { Drink de boas-vindas, } \\
\text { oferecido aos hóspedes. }\end{array}$ & $\begin{array}{l}\text { Drink de boas- } \\
\text { vindas }\end{array}$ & Welcome drink & Drink Bienvenido \\
\hline Youth hostel & $\begin{array}{l}\text { Albergues para a } \\
\text { juventude. }\end{array}$ & $\begin{array}{l}\text { Albergues para a } \\
\text { juventude }\end{array}$ & Youth hostel & Albergue juvenil \\
\hline
\end{tabular}

